\title{
Prescrição em Atos de Concentração
}

\author{
Marcio de Carvalho Silveira Bueno'
}

\section{Introdução}

É uma honra participar do relançamento da Revista de Direito Administrativo.

Nos parece bastante feliz a idéia de incluir na pauta da Revista comentários sobre acórdãos proferidos pelo Conselho Administrativo de Defesa Econômica (CADE), uma vez que o direito concorrencial vem ganhando cada vez mais importância no Brasil e no Mundo, ao mesmo tempo em que questões tradicionais do Direito Administrativo vêm também sendo suscitadas e discutidas no âmbito do Conselho e de outras agências reguladoras.

Dentre as diversas e interessantíssimas decisōes do CADE, nos foi indicada uma na qual o debate foi intenso (Ato de Concentração no 8012.003315/2004-13 - Requerentes: E. I. Du Pont de Nemours and Company, Du Pont do Brasil S.A., e Griffin Corporation of Valdosta Geórgia). ${ }^{2}$ Nada menos do que 5 dos 7 membros do plenário optaram por redigir votos vogais para melhor expor os fundamentos de suas conclusōes, tendo havido um intervalo de mais de 4 meses entre o início e a conclusão do julgamento.

A discussão concentrou-se numa questão própria de Direito Administrativo a prescrição. Ela foi discutida tanto em relação à aplicação da multa pela apresentação intempestiva de atos de concentração, como também ao exame do próprio mérito de atos de concentração não submetidos tempestivamente ao órgão.

\footnotetext{
Advogado e Conselheiro do IBRAC.

2 Julgado em 22 de fevereiro de 2006. Relatado pelo Conselheiro Luis Fernando Rigato Vasconcellos. Acórdão publicado no DOU em 17 de março de 2006.
} 
Parece-nos particularmente interessante aprofundar a discussão sobre este último tema, ou seja, verificar se o decurso do tempo limita ou não o controle pelo CADE de atos potencialmente lesivos à concorrência. No caso comentado, a unanimidade dos conselheiros manifestou entendimento no sentido de que o órgão pode a qualquer tempo ordernar a desconstituição da operaçāo ou outras restrições, sendo imune à prescrição administrativa.

Permitimo-nos acreditar que essa não é a mais adequada interpretação da lei. Mas antes de expormos nossas razōes, cumpre-nos oferecer uma breve descrição do caso concreto e do julgamento.

\section{O caso concreto}

Em 1998, as empresas E.I. du Pont de Nemours and Company ("DU PONT") e Griffin Corporation of Valdosta ("GRIFFIN") se associaram para constituir uma sociedade (joint venture) denominada Griffin LLC ("JV"), a qual posteriormente criou uma subsidiária brasileira (Griffin Brasil Ltda.).

Muito embora essa transação não tenha sido submetida à aprovação do CADE, na época de sua realização, posteriormente, quando, em 2003, a associação foi desfeita, por meio da aquisição por parte da DU PONT das ações da JV detidas pela GRIFFIN, o Sistema Brasileiro de Defesa da Concorrência ("SBDC") foi notificado, nos termos do artigo 54 da Lei $n^{0} 8.884 / 94$.

O referido dispositivo legal prevê que negócios potencialmente lesivos à livre concorrência (caput), incluindo fusões, aquisições e joint ventures $\left(\$ 3^{\circ}\right)$, devem ser submetidos à apreciação do CADE, no prazo de 15 dias úteis de sua realização $\left(\$ 4^{\circ}\right)$.

Apesar de reconhecer que a operação em exame naqueles autos (o desfazimento da joint venture) nāo acarretava efeitos anticompetitivos, o Conselheiro Thompson de Almeida Andrade, então relator daquele processo, observando que o ato de constituição da JV não havia sido apresentado ao SBDC, expediu um ofício dirigido às requerentes manifestando seu entendimento de que referida transação deveria ser submetida ao CADE, diante do que as empresas optaram por efetivamente apresentar os documentos e informações relativos ao ato de constituiçāo da joint venture, formando um processo próprio.

Foi a partir do substancial lapso de tempo entre a realização da operaçāo e a expedição do oficio que foram suscitadas as questões jurídicas que permearam o debate entre os Conselheiros no julgamento do caso.

Tendo a constituição da joint venture sido notificada apenas 6 anos após a realização da mesma, a violação do prazo de 15 dias úteis estabelecido no $\$ 5^{\circ}$ do artigo 54 da Lei $n^{\circ} 8.884 / 94$ era evidente, mas as requerentes argumentaram tanto a nāoobrigatoriedade de notificação (por se tratar de ato realizado no exterior, sem efei- 
tos lesivos no mercado brasileiro), como o descabimento da aplicação da multa em virtude de alegada prescrição da pena administrativa, com base no artigo $1^{\circ} \mathrm{da}$ Lei $n^{2} 9.873 / 99$, o qual prevê:

"Art. $1^{\circ}$ Prescreve em cinco anos a ação punitiva da Administração Pública Federal, direta e indireta, no exercício do poder de polícia, objetivando apurar infração à legislação em vigor, contados da data da prática do ato ou, no caso de infração permanente ou continuada, do dia em que tiver cessado."

Com isso, surgiu a primeira das questões tratadas no julgamento. A outra apareceu como conseqüência do esforço de alguns Conselheiros de fazer a distinção entre a aplicação da multa por intempestividade da apresentação e a competência do CADE para a aprovação do ato de concentraçāo.

No julgamento do caso, foram manifestadas posições divergentes em relação a essas duas questões, tendo sido proferidos vários votos escritos, os quais relatamos a seguir.

\section{Voto do Relator}

O Conselheiro Luis Fernando Rigato Vasconcellos, então relator do processo, refutou ambos os argumentos apresentados em defesa das requerentes. Em relaçāo ao primeiro, fez referência ao entendimento já consolidado no Conselho de que, uma vez enquadrados nos critérios objetivos, de faturamento e participação de mercado, fixados no $₫ 3^{\circ}$ do artigo 54 , é obrigatória a notificação, independentemente de a operaçāo gerar ou não dano à concorrência.

Sobre $o$ argumento de prescrição, o Conselheiro Rigato considerou que, consistindo a não-apresentação da operação em uma omissão continuada, o termo inicial do prazo prescricional somente teria tido início a partir da efetiva submissão da operação ao CADE:

"As partes poderiam, a qualquer momento, por livre e espontânea vontade, apresentarem tal operação, mas se recusaram a submeterem tal ato ao $S B D C$, mantendo assim o descumprimento, a infração à legislação em vigor.

As Requerentes poderiam cessar a omissão, simplesmente notificando o ato ao Sistema Brasileiro de Defesa da Concorrência. Tal atitude colocaria fim à intempestividade, o que comprova que o ato se manteve no tempo. Ao invés disso, mantiveram sua atitude omissiva, perpetuando a infração ao mandamento legal.

Com efeito, a omissão continua perdurando, desde o momento em que se inicia a intempestividade (após $015^{\circ}$ dia útil posterior à realização do ato), até a efetiva apresentação da operação ao SBDC. A cada dia em que o ato não foi apresentado, prolongou-se a intempestividade, manteve-se o descumprimento aos ditames legais." (grifos no original) 
Assim, com base na parte final do artigo $1^{\circ}$ da Lei $n^{\circ} 9.873 / 99$, que prevê, para os casos de infração continuada, que a contagem do prazo prescricional só tem início a partir do dia em que tiver cessado a infração e estiver caracterizada a conduta das requerentes como uma persistente omissão das requerentes, votou o Conselheiro-Relator pela aplicação de multa equivalente a $\mathrm{R} \$ 766.050,71$.

\section{Voto do Conselheiro Pfeiffer}

Ainda na mesma sessão de julgamento, o Conselheiro Roberto Augusto Castellanos Pfeiffer proferiu voto vogal, manifestando divergência em relação à questão da prescrição da pena por intempestividade da notificação da operação, mais especificamente em relação à natureza da infração e, conseqüentemente, no que tange ao termo inicial do prazo prescricional.

"Entendo que o tipo da infração que cuida o art. $54, \$ 5^{\circ}$ da Lei n" 8.884/94 é a não apresentação de ato de concentração no prazo estipulado, ou seja, a não apresentação de ato de concentração até o $15^{\circ}$ dia útil da realização da operação. Assim, entendo que a infração ocorre no $16^{\circ}$ dia da realização do ato, quando, então restará consumada - infração instantânea, devendo, assim ser aplicada multa por intempestividade na apresentação do ato de concentração no prazo prescricional de 05 (cinco) anos, contado a partir da data da prática do ato, do 16 ${ }^{\circ}$ dia útil da realização da operação."

Destarte, ao contrário do Relator, que considerou a inobservância do prazo de 15 dias úteis como uma infração permanente, porquanto dure o descumprimento de tal preceito, o Conselheiro Pfeiffer, em interpretação diametralmente oposta, a entende como instantânea, já plenamente caracterizada e encerrada a partir do dia seguinte ao termo final do prazo estabelecido no $\$ 4^{\circ}$ do artigo 54 da Lei no ${ }^{\circ} 8.884 / 94$.

Por outro lado, em seu voto, fez questāo de ressaltar a distinção entre a imposição da multa pelo não-cumprimento do prazo de notificação e a apreciação do mérito da operação. Para ele, enquanto a ação punitiva da intempestividade seria passível de prescrição na forma da Lei $n^{\circ} 9.873 / 99$, a obrigação de submissão dos atos de concentraçāo e a possibilidade de intervenção por parte do CADE visando impedir atos lesivos à livre concorrência seria imprescritível.

"Verifica-se pela leitura do mencionado dispositivo [ $\$ 7^{\circ}$ do artigo 54 da Lei $\mathrm{n}^{\circ}$ 8.884/94] que 'a eficácia dos atos de que trata este artigo condiciona-se à sua aprovação, caso em que retroagirá à data de sua realização', ou seja, a obrigação de apresentação dos atos que 'possam limitar ou prejudicar a livre concorrência, ou resultar na dominação de mercados relevantes de bens ou serviços' estão sujeitos a condição suspensiva, assim, enquanto não analisados pelo SBDC não são eficazes." 
O voto em apreço faz referência, ainda, ao artigo 199, I, do Código Civil, segundo o qual, "pendendo condição suspensiva" não corre a prescrição. Assim, segundo o Cons. Pfeiffer, como a aprovação do ato pelo CADE configurar-se-ia uma condição suspensiva, imposta pela lei, o prazo prescricional somente passaria a ter sua contagem iniciada a partir da própria aprovação pelo órgão, o que, na prática, significa que o controle do referido negócio pelo Conselho seria ad eternum, imprescritivel.

\section{Voto do Conselheiro Prado}

Estabelecida a divergência acerca do termo inicial da prescriçāo da aplicação da pena pela inobservância do prazo para submissão dos atos de concentração, o Conselheiro Luiz Carlos Delorme Prado pediu vistas dos autos para aprofundar-se na questão.

Apesar de praticamente acompanhar integralmente a manifestação do Cons. Pfeiffer, o Cons. Prado proferiu voto no qual traz elementos adicionais a corroborar ser a inobservância do prazo de submissão uma infração instantânea, conquanto possa ter efeitos permanentes, hipótese que, no entanto, segundo ele, não impede o curso do lapso prescricional.

Asseverou ainda, no seu voto, que: "[e]ntendimento diverso levaria à imprescritibilidade do direito do CADE em aplicar multa por inobservância do prazo de apresentação de atos de concentração, raciocínio que não se coaduna com os modernos sistemas jurídicos de todo o mundo".

Apesar do reconhecimento da incompatibilidade da hipótese de imprescritibilidade com o Estado de Direito, o Cons. Prado, em relação ao controle de atos de concentração, a admite.

“A Lei n" 8.884/94 determina que compete ao Plenário do CADE zelar pela repressão ao abuso do poder econômico, o que demanda, por óbvio, a análise, em qualquer época, de condutas que estejam ocorrendo e se subsumam às normas antitruste. Portanto, uma operação não apresentada implica no risco imprescritivel de que uma análise posterior pelo CADE venha a estabelecer restriçōes ou determinar o desfazimento do ato de concentração."

Destarte, de acordo, com esse entendimento, o CADE não perderia a competência para controlar atos enquadrados no caput e $\mathbb{3} 3^{\circ}$ do artigo 54 em virtude do decurso do tempo. Poderia, por exemplo, impor hoje uma restrição a um contrato de fusão firmado há 15 anos.

\section{Voto do Conselheiro Cueva}

Também o Conselheiro Ricardo Villas Bôas Cueva pediu vistas para "melhor analisar a questão da prescrição à luz das Leis nº 8.884/94 e nº 9.873/99". 
$\mathrm{Na}$ leitura dele, corroborando o entendimento do Relator, o "dever de comunicar o ato de concentração às autoridades subsiste ainda que descumprido o prazo legalmente estipulado de 15 (quinze) dias, o que consubstancia infrarão de caráter permanente, vez que se encontra sob exclusiva autonomia da vontade do agente a cessação da conduta juridicamente apenada, qual seja, a não-apresentação de operaçōes no prazo previsto".

Recorrendo a ilustres jus-penalistas, busca caracterizar a inobservância do prazo como infração permanente, tal como o crime de seqüestro, na qual a consumiação se prolonga no tempo, dependente da ação do sujeito, chegando a afirmar que "a cessação da intempestividade depende única e exclusivamente da vontade das requerentes [...] as requerentes têm a disposição de cessar a infração e, enquanto isso não ocorre, a consumação da intempestividade vai se perpetuando no tempo". Em vista dessa interpretação, o Cons. Cueva não reconheçe a prescrição.

\section{Voto do Cons. Schuartz}

Por fim, em voto-vista, o Cons. Luis Fernando Schuartz atacou especialmente a questão da caracterizaçāo da infraçāo como instantânea. Com base em criteriosa leitura do dispositivo legal que estabelece a multa em questão, ele identifica que a hipótese de incidência da pena não é subtrair da apreciação do CADE ato de apresentação obrigatória de acordo com artigo 54 da Lei $\mathrm{n}^{\mathrm{0}}$ 8.884/94, mas sim a inobservância do prazo fixado no $\mathbb{9} 4^{\circ}$.

A partir dessa observação, o Cons. Schuartz conclui que "a consumação da infração, nesse sentido, é pontual, e coincide com o instante seguinte ao do fechamento do protocolo da SDE no dia útil em que vence o prazo estabelecido pela lei". Ainda que as partes se abstenham de submeter a operação à apreciação do CADE em momento posterior, o descumprimento do preceito legal já teria sido consumado, ao contrário do que se verificaria caso a hipótese de incidência da sanção fosse a não-comunicação da transação ao CADE. Apenas nesse caso estar-se-ia diante de uma infração permanente, cuja consumação perduraria enquanto o ato não fosse devidamente notificado.

Na sua manifestação, o Cons. Schuartz ainda refuta as analogias com crimes permanentes, como o de seqüestro. Conforme asseverou em seu voto, no crime de seqüestro a permanência do estado de coisas (privação da liberdade da vítima) integra o tipo penal, ao contrário da infraçāo descrita no $\mathbb{\$} 5^{\text {o }}$ do artigo 54 da Lei no 8.884/94, que simplesmente faz referência à inobservância do prazo.

Em contrapartida, a persistência na não-apresentação do ato de concentraçāo não poderia ser considerada uma continuação da inobservância do prazo legal, já que esse estado de coisas (subtração da operação ao exame pelo CADE) não seria um elemento constitutivo do tipo legal.

"Nesse sentido, a consumação do ilícito se esgota com o ato da não notificação, que se verifica após o término do referido prazo. O estado da ausência de notificação, 
que perdura após o momento em que ocorre o ato da não notificação tempestiva $e$ com ela. a infração, não mais deixa-se alcançar pela norma do $\mathbb{S} 5^{\circ}$, podendo servir, a partir daí, exclusivamente como fator para a quantificação da sanção aplicável."

Assim, o entendimento do Cons. Schuartz aproximou-se bastante do que foi sustentado pelos Cons. Pfeiffer e Prado, mas acrescentou ainda um novo argumento.

Segundo ele, caso a infração perdurasse enquanto a operação não fosse notificada, estar-se-ia diante de uma hipótese de prescrição impossível, uma vez que "feita a notificação, a única hipótese de incidência da prescrição seria aquela prevista no $\$ 1$ " do citado artigo $1^{\circ}$ da Lei $n^{\circ}$ 9.873/99, a saber a paralisação do procedimento administrativo por mais de 3 anos", ou seja, a prescriçāo intercorrente. "Com isso, a ação punitiva do CADE diante de constatação da infração da norma do $\$ 5^{\circ}$ do artigo 54 tornar-se-ia virtualmente imprescritivel".

\section{Resultado do Julgamento}

O Conselheiro Paulo Furquim de Azevedo e a Presidente Elizabeth Farina acompanharam o posicionamento já, naquela altura, majoritário, de que a pretensão do CADE para aplicação da multa pela intempestividade da apresentação da operação já estaria prescrita, em decorrência do decurso de mais de 5 anos da data em que o ato deveria ter sido notificado, vencidos os Conselheiros Rigato e Cueva que sustentavam tratar-se de delito permanente, pelo que a contagem do prazo prescricional somente teria início a partir da cessação da intempestividade, isto é, da data em que foi a constituição da joint venture notificada ao SBDC.

Vale notar ainda que o plenário, por unanimidade, aprovou a operação em tela, reconhecendo implicitamente, portanto, ainda deter competência para examinar o mérito do ato realizado em 1998, ou seja, cerca de 8 anos antes.

\section{Nossas Consideraçōes sobre o Acórdão}

A nosso ver, algumas consideraçōes parecem relevantes sobre o tema da prescrição, tanto em relação à aplicação da multa por intempestividade, como do próprio exame de mérito de atos subsumíveis ao caput e $\$ 3^{\circ}$ do artigo 54 da Lei $\mathrm{n}^{\circ}$ $8.884 / 94$, visto que a questão, muito provavelmente, voltará a ser examinada pelo Conselho no futuro.

Na verdade, não há como avançar no exame da questão sem darmos um passo atrás para compreendermos melhor o fenômeno da prescrição, especialmente seu fundamento e os princípios jurídicos que o informam, pois esses necessariamente devem nortear a interpretação de toda norma legal específica que dela trate. 
Como muito bem lembra o Prof. Luís Roberto Barroso em primoroso parecer sobre o tema da prescriçāo administrativa, a segurança, incluindo-se no seu conceito a previsibilidade dos efeitos jurídicos e a estabilidade das situaçōes constituídas, é um dos valores essenciais de um Estado Democrático de Direito.

"Em nome da segurança jurídica, consolidaram-se institutos desenvolvidos historicamente, com destaque para a preservação dos direitos adquiridos e da coisa julgada. É nessa mesma ordem de idéias que se firmou e difundiu o conceito de prescrição, vale dizer, da estabilização das situações jurídicas potencialmente litigiosas por força do decurso de tempo."3

Constituindo a prescrição em instrumento erigido sobre um valor essencial do Estado de Direito, é necessária a conclusāo de que apenas muito excepcionalmente poderão ser estabelecidas regras de imprescritibilidade.

"Em qualquer dos campos do direito, a prescrição tem como fundamento lógico o princípio geral de segurança das relações jurídicas e, como tal, é a regra, sendo a imprescritibilidade situação excepcional. A própria Constituição Federal de 1988 tratou do tema para prever as únicas hipóteses em que se admite a imprescritibilidade, garantindo, em sua sistemática, o princípio geral da perda da pretensão pelo decurso do tempo." 4

Assim, inexistindo expressa previsão constitucional, é proibido não somente a edição de leis que estabeleçam outras hipóteses de imprescritibilidade, como também interpretações de textos legais que levem a situaçōes em que a operação da prescrição se torne impraticável.

Portanto, mesmo diante da omissão legal, estabelecendo expressamente um prazo prescricional, não é permitido concluir-se que se estará diante de uma hipótese de imprescritibilidade.

“O fato de não haver uma norma dispondo especificamente acerca do prazo prescricional, em determinada hipótese, não confere a qualquer pretensão a nota da imprescritibilidade. Caberá ao intérprete buscar no sistema normativo, em regra através da interpretação extensiva ou da analogia, o prazo aplicável." 5

Entendemos serem essas observaçōes preliminares acerca do enquadramento jurídico do fenômeno da prescrição absolutamente pertinentes, uma vez que é a partir desses conceitos que devem ser examinadas as questões suscitadas no acórdāo ora em comento.

\footnotetext{
A prescrição administrativa no direito brasileiro antes e depois da Lei $n^{\circ} 9.873 / 99$, publicado na Revista Diálogo Jurídico, Salvador, ano I, v. I, n" 4, p. 3, 7/1.

+ Idem, p. 4.

5 Idem, p. 5.
} 


\section{Prescrição da Multa por Intempestividade}

Como bem notou o Conselheiro Schuartz, a interpretação proposta pelo Relator teria como conseqüência prática tornar a não-submissão de atos de concentração à aprovação do CADE no prazo legal uma infração imprescritível, isto é, passível de punição a qualquer tempo, independentemente do decurso de qualquer prazo, ainda que de, por exemplo, 20 anos.

Com efeito, se o descumprimento do dever de apresentação da operação caracteriza uma infração permanente, conforme também sustenta o Conselheiro Cueva, o prazo prescricional da ação punitiva somente teria início se e quando as partes formalmente notificassem o SBDC da realização do negócio. Ou seja, a punição desse ato ilícito seria então, na prática, imprescritível.

Não nos parece que essa interpretação seja lícita face os preceitos jurídicos informadores do fenômeno prescricional acima retomados, segundo os quais a imprescritibilidade seria excepcional e exigiria previsão constitucional.

Não bastasse esse argumento, a construção hermenêutica da hipótese de incidência da penalidade em comento desenvolvida pelos Conselheiros Pfeiffer, Prado e Schuartz parece-nos mais plausível.

De fato, transformando o $\$ 5^{\circ}$ do artigo 54 numa proposição lógica (SE as partes não notificarem dentro do prazo de 15 dias úteis contados da realização da operação, ENTÃO devem ser apenadas com multa pecuniária), resta muito claro que já no $16^{\circ}$ dia útil subseqüente à data de realizaçāo da operação a infração estaria plenamente caracterizada e consumada, independentemente de qualquer outro comportamento futuro das partes, de forma que o prazo prescricional para sancionar a mesma deveria ter, desde então, sua contagem iniciada.

\section{Prescrição do Controle de Atos}

Embora a questão da prescrição da competência para aprovar atos de concentração tenha aparecido explicitamente apenas nos votos escritos dos Conselheiros Pfeiffer e Prado, nos debates orais o tema foi retomado, tendo o Cons. Cueva corroborado o entendimento de que o dever de apresentar o ato e, conseqüentemente, do CADE intervir sobre o mesmo nunca prescreveria, por, segundo ele, não se enquadrar na Lei $n^{\circ} 9.783 / 99$.

Houve, na verdade, por parte dos Conselheiros um consenso, em torno da imprescritibilidade da competência do órgão para aprovar atos enquadráveis no caput e $\mathbb{3} 3^{\circ}$ do artigo 54 da Lei $n^{\circ} 8.884 / 94$, o que resultou na decisão unânime de conhecer do ato de concentração em exame.

Data máxima vênia, parece-nos estar essa tese em dissonância com os fundamentos do Estado de Direito. 
Como aponta a doutrina, a prescriçāo é a regra e a imprescritibilidade excepcional.

Diante disso, mesmo que se admita ser procedente o argumento segundo o qual a regra de prescrição estabelecida no artigo $1^{\circ}$ da Lei no ${ }^{\circ}$ 9.873/99 não é aplicável aos atos de concentração, em virtude de não se configurar nesse caso uma ação punitiva, mas uma intervenção na iniciativa privada de caráter diverso, não seria lícito concluir imediatamente estar-se diante de um caso de imprescritibilidade.

Conforme propõe o Prof. Fabio Medina Osório, em consonância com as citações anteriores, mesmo "[i]nexistindo prazo prescricional a determinada sanção administrativa, imperioso o recurso à analogia, suprindo-se eventual omissão do legislador, que está obrigado, constitucionalmente a regular essa matéria". ${ }^{6}$

Muito embora possa se questionar o prazo que venha a ser considerado o melhor parâmetro para a prescrição do controle de atos de concentração, parece-nos inevitável que ele exista, uma vez que o imperativo de estabilização das relaçōes entre administrados e Administração impōe a necessidade de se fixar um tempo a partir do qual a administração não mais pode intervir sobre atos realizados no passado.

Dentro do mesmo espírito estabilização das relações, estabelece o artigo 54 da Lei $\mathrm{n}^{0}$ 9.784/99 que a Administração perde o direito de anular atos administrativos eivados de vícios, inclusive de legalidade, passados 5 anos contados da data em que foram praticados.

Vale ressaltar, ainda nesse tocante, que até mesmo a pretensão punitiva de atos tipificados como crimes, como o homicídio, é passível de prescrição.

Portanto, não seria minimamente razoável supor que o controle de atos de concentração estaria imune à prescrição ou que deveria receber um tratamento mais rigoroso, inclusive do que aquele atribuído no âmbito criminal.

Tampouco, parece-nos razoável o argumento do Cons. Pfeiffer segundo o qual o $\$ 7^{\circ}$ do artigo 54 da Lei $\mathrm{n}^{\circ} 8.884 / 94$, que condiciona a eficácia dos atos à aprovaçāo do CADE, constituiria uma condição suspensiva, o que, segundo ele, impediria o decurso do prazo prescricional em virtude de expressa disposição do Código Civil.

Com efeito, mencionado parágrafo da lei antitruste não estabelece uma condição suspensiva, mas sim resolutiva. Caso efetivamente tratasse de condiçāo suspensiva, os atos subsumíveis ao artigo 54 deveriam permanecer sem produzir efeitos enquanto não fossem aprovados pelo CADE. O disposto na Lei $\mathrm{n}^{\circ} 8.884 / 94$ prevê justamente o contrário. Isto é, que os atos, muito embora tenham sua eficácia sujeita à aprovação do CADE, produzem efeitos desde o momento de sua assinatura até o julgamento pelo Conselho. Apenas na hipótese de não ser aprovado,

\footnotetext{
Direito administrativo sancionador. Sāo Paulo: Revista dos Tribunais, 2000, p. 414.
} 
o ato deixaria de produzir efeitos, situaçāo essa típica de uma condição resolutiva, a qual não é fator impeditivo da prescrição.

Assim, entendemos que, ao contrário do quanto fora decidido pelo CADE no processo em comento, é absolutamente passivel de prescrição a intervenção do órgão sobre os atos enquadráveis no caput e/ou $\$ 3^{\circ}$ do artigo 54 da Lei no 8.884/94, ainda que os mesmos manifestamente representem prejuízos à livre concorrência. Isto é, decorrido o prazo prescricional (de 5 anos ou outro período de tempo eventualmente considerado mais adequado), não cabe mais ao Conselho aprovar ou desaprovar tais transações, nem impor qualquer restrição às mesmas.

\section{Conclusão}

O julgado que ora comentamos é um dos marcos iniciais do debate sobre o limite temporal da competência do CADE perante atos de concentração. Nele, é importante ressaltar, os Conselheiros não vislumbraram qualquer risco à concorrência, pelo que decidiram pela aprovação irrestrita da operaçāo. A matéria certamente exigirá maior atenção caso o Conselho se defronte com uma transação não notificada dentro de 5 anos contados do prazo legal e que gere preocupaçōes concorrenciais. Nessa hipótese, caso deseje desaprovar ou impor restrições ao negócio, a questão da prescriçāo será objeto de grande atençāo por parte do Plenário e das empresas.

Em relação à prescrição da aplicação da pena por intempestividade, parecenos que a tendência do CADE é de consolidar a posiçāo já majoritária no sentido de que o termo inicial da contagem do prazo prescricional se dá desde o primeiro momento após a inobservância do $\$ 4^{\circ}$ do artigo 54 da Lei nº 8.884/94. 